\title{
Situações-problema como Estratégia Didática para o Ensino dos Modelos Atômicos
}

Mauro de Souza Lima Prates Júnior

Jose Euzebio Simões Neto

\section{Resumo}

O presente trabalho teve como objetivo principal analisar como a estratégia didática do uso das situações-problema pode auxiliar no processo de ensino e aprendizagem do conteúdo de modelos atômicos no Ensino Médio, em uma escola da rede estadual de Minas Gerais da região metropolitana de Belo Horizonte. Elaboramos duas situações-problema, com contextos relacionados aos modelos atômicos. Durante a intervenção didática, ministramos aulas sobre o tema como Sistema de Recursos para a resolução das situações-problema. A obtenção dos dados foi feita por observação durante as intervenções, questionários a priori e a posteriori e as soluções apresentadas às situaçõesproblema pelos grupos de alunos. A resolução das situações-problema pelos estudantes contribuiu de forma significativa para o entendimento do conceito de modelos atômicos, pois 35\% das respostas foram consideradas satisfatórias, um bom índice para o contexto desta pesquisa.

Palavras-chave: situações-problema, modelos atômicos, ensino de química.

\section{Abstract \\ Problem-Situations as Didactic Strategy for the Teaching of the Atomic Models}

This study aimed to analyze how the teaching strategy of using problemsituations can assist in the teaching and learning of the content of atomic models in high school, in Minas Gerais, in metropolitan region of Belo Horizonte. We have prepared two problem-situations, with contexts related to the atomic models. During the didactic intervention, we gave classes about the subject as a way to appeal to there solution of problem-situations. Data collection was done by observation during the intervention, questionnaires were made before and after classes and solutions to problem-situations presented by groups of students. The resolution of problem-situations by students contributed significantly to the understanding of the concept of atomic models, as 35\% of the responses were considered satisfactory, a good index for the context of this research.

Keywords: problem-situations, atomic models, chemistry teaching. 


\section{Introdução}

Um dos grandes problemas encontrados no ensino de ciências nas escolas do Brasil está relacionado ao método de ensino escolhido pelo professor. Basicamente são observados os métodos tradicionais, conhecidos por diversas alcunhas, tais como: modelo baldista (CÂMARA DOS SANTOS, 2002) ou da educação bancária (FREIRE, 2005). Esses modelos se baseiam nas máximas quase totalmente aceitas no senso comum de que "educador é o que sabe e educandos, os que não sabem"; "educador é o que pensa e os educandos os que escutam e replicam" e "o educador é o sujeito do processo de ensino e aprendizagem e os educandos meros objetos".

No entanto, pensamos que as formas tradicionais de ensino que fazem com predominância o uso de exercícios - mecanismos automatizados priorizando a memorização - não são capazes de formar cidadãos críticos, pois não os fazem aprender ciências como uma realidade e sim como uma entidade totalmente desligada dos fenômenos reais, requerendo um poder maior da memória (para fatos, equações e definições) do que o estabelecimento de relações entre o que se ensina e o que explica os fenômenos da natureza (MORTIMER, MACHADO, ROMANELLI, 2000).

A complexidade do mundo atual não mais permite que o Ensino Médio seja encarado apenas como um preparatório para os exames de seleção para as universidades e faculdades, em que o estudante é um perito, pois é treinado em resolver questões engessadas, que exigem sempre uma mesma resposta padrão. A vida exige que cada indivíduo se posicione, julgue e seja capaz de tomar decisões, arcando com as consequências da decisão tomada, sendo responsabilizado pelas escolhas feitas. Essas são capacidades mentais construídas nas interações sociais vivenciadas na escola, em situações complexas que exigem novas formas de participação. Para isso, não servem componentes curriculares desenvolvidos com base em treinamento para respostas padrão. Um projeto pedagógico escolar adequado não é avaliado pelo número de exercícios propostos e resolvidos, mas pela qualidade das situações propostas, em que os estudantes e os professores, em interação, terão de produzir conhecimentos contextualizados. (BRASIL, 2006).

Para a química, é comum encontrarmos currículos deveras tradicionais, focados na aprendizagem de conteúdos puramente conceituais. Porém, além dos conceitos, existem ainda conteúdos ligados às atitudes (comportamentos, valores) e conteúdos ligados aos procedimentos, estes integrados em atividades mais amplas que, de modo geral, envolvem a utilização de vários processos de ação. Dentre essas atividades, podemos destacar a resolução de problemas. (POZO; GOMEZ CRESPO, 2009)

Não é fácil pensar em um processo de ensino e aprendizagem baseado na resolução de problemas, sem de fato entender o que é um problema. Sendo assim, é importante apresentar distinções entre as definições e características de exercícios e problemas. De acordo com Batinga e Teixeira (2009), podemos entender o exercício como: 
"Situação em que o aluno dispõe de respostas, utilizando de mecanismos automatizados que levam a solução de forma imediata, priorizando a memorização de regras, fórmulas, equação e algoritmos. O exercício é normalmente utilizado para operacionalizar um conceito, treinar um algoritmo e o uso de técnicas, regras, equações ou leis químicas, e para exemplificar." (p.04).

Para as mesmas autoras, problema é:

"Situação que um sujeito ou um grupo quer ou precisa resolver e para a qual não dispõe de um caminho rápido e direto que leve à solução. Seguindo esse conceito, uma situação somente pode ser concebida como um problema na medida em que os sujeitos atribuam um reconhecimento dela como tal, e quando requer dos que a tentam resolver um processo de reflexão ou uma tomada de decisão sobre a estratégia a ser seguida no processo de resolução de problemas. Um problema é uma situação nova ou diferente do que já foi aprendido, que requer a busca de estratégias ou de conhecimentos, ou de técnicas, ou ambos, para encontrar sua solução." (BATINGA; TEIXEIRA, 2014, p.25).

Pozo e Gómez Crespo (2009) classificam os problemas em três diferentes tipos, a saber: problemas qualitativos, problemas quantitativos e pequenas pesquisas. Podemos entender um problema qualitativo como problemas abertos, nos quais os estudantes devem analisar as situações apresentadas em contextos científicos ou cotidianos, para interpretá-las a partir dos seus conhecimentos prévios ou em vias de aprendizagem. Já um problema quantitativo envolve o uso da linguagem matemática, exigindo a manipulação de números para obtenção de uma solução. Por fim, as pequenas pesquisas são atividades que simulam o trabalho científico, a partir de diversos procedimentos de trabalho em laboratório escolar, ou fora dele.

Podemos então dizer que exercícios e problemas são ferramentas bastante diferentes, cabendo ao professor saber fazer o uso correto e adequado de cada, pois, o mesmo possui flexibilidade para adaptar seu currículo de acordo com os objetivos que tem para usar exercícios ou problemas, além das necessidades, realidades regionais e as características dos estudantes. Ainda, é fundamental que o professor tome consciência que as atividades elaboradas a partir de problemas exigem um compromisso maior dos estudantes para resultados significativos.

A partir das dificuldades apresentadas pelos docentes em distinguir exercício de problema, além da necessidade de se usar problemas com contextos que sejam reconhecíveis e interessantes para os estudantes, parece necessária uma melhor formação dos professores, ação que, em conjunto com outras medidas políticas e econômicas, pode transformar o ensino de química na direção de uma maior qualidade. Assim, como afirma Simões Neto (2009), os cursos 
superiores de licenciatura em química devem apresentar estratégias didáticas diferenciadas e motivadoras, para que os licenciandos possam aplicar quando ingressarem nas escolas ou mesmo nos estágios obrigatórios. Uma potente estratégia didática baseada na resolução de problemas é o trabalho com situações-problema.

Adotamos para esta pesquisa a visão de Meirieu (1998) sobre situação-problema (SP), que a define como:

\begin{abstract}
"Uma situação-didática na qual se propõe ao sujeito uma tarefa que ele não pode realizar sem efetuar uma aprendizagem precisa. E essa aprendizagem, que constitui o verdadeiro objetivo da situação problema, se dá ao vencer obstáculos na realização da tarefa." (p.189)
\end{abstract}

Para fazer o uso desta estratégia é necessário criar condições para que o sujeito consiga efetuar as solicitações operacionais mentais, dentro dos limites individuais, construindo o conhecimento, sendo esta construção o verdadeiro objetivo da situação-problema. Na literatura (AZEVEDO, 2004; POZO; GOMÉZ CRESPO, 2009), encontramos alguns direcionamentos sobre as situações-problemas:

\title{
A) Devem ser interessantes para o aluno, de preferência evolvendo aspectos das relações CTS.
}

O contexto escolhido como situação é determinante para o sucesso da situação-problema. Para cumprir o que Meirieu (1998) chama de função erótica, ou seja, despertar o interesse em saber, aprender e crescer do ponto de vista cognitivo, os contextos escolhidos devem ser atuais, de relevância local ou global e que façam parte, de alguma forma, do cotidiano dos estudantes para os quais são dirigidos.

B) Devem ser problemas abertos que permitam resolução inicial qualitativa, baseada no levantamento de hipóteses.

Uma situação-problema deve ser aberta, sem dirigir as possibilidades de resposta e deve ser resolvida a partir do levantamento de hipóteses, para testes que as confirmem ou as refutem.

C) Devem ser reconhecidas pelos alunos como um desafio intelectual, porém, não deve ser tão difícil para que esse aluno busque evitar a aprendizagem.

As situações-problema devem exigir, para sua solução, que um obstáculo seja transposto, e é neste processo que está a aprendizagem. No entanto, se o obstáculo é muito distante dos conhecimentos prévios que podemos mobilizar para sua superação, naturalmente buscamos respostas que evitam a aprendizagem:

"Sempre inventamos para não termos que aprender. Fabricamos e trocamos objetos manufaturados que podemos utilizar com economia, ignorando todas as aprendizagens que tornaram possível sua elaboração. É por isso que não devemos atribuir à má vontade do aluno o fato de tentarem sempre executar o 
projeto sem aprender. Não devemos estranhar o fato de procurarem sistematicamente a facilidade, o amigo que já sabe fazer e o objeto já pronto" (MEIRIEU, 1998, p. 172).

\title{
D) Ao professor é fundamental saber para quem a situação-problema deve ser proposta.
}

Tão importante como a definição do contexto e do obstáculo, é reconhecer o estudante, para evitar que o contexto seja impróprio, o obstáculo intransponível ou ambas as situações.

Meirieu (1998) aponta as principais características que deve apresentar uma situaçãoproblema para que consista em importante dispositivo dentro de uma estratégia didática inovadora:

\begin{abstract}
"Propõe-se aos sujeitos a realização de uma tarefa. A tarefa só pode ser executada se o obstáculo for transposto. A transposição do obstáculo deve representar um patamar no desenvolvimento cognitivo do sujeito. O obstáculo deve apresentar um sistema de restrições a fim de que os sujeitos não executem o projeto sem enfrentar os obstáculos. Deve ser fornecido aos sujeitos um sistema de recursos (materiais e instruções) para que eles possam vencer o obstáculo." (p.173).
\end{abstract}

Ou seja, toda situação-problema deve apresentar: um contexto (e este deve ser interessante para o estudante); um obstáculo (que deve ser transposto, sendo este movimento de superação o real objetivo da situação-problema); um sistema de restrição (instalado na própria situação-problema, para evitar que respostas que não superem o obstáculo sejam fornecidas); e, por fim, um sistema de recursos, que consiste em algum material físico ou digital, instruções-alvos ou atividades dialógicas em sala de aula), que forneçam as condições para construção de conhecimento e resolução da situação-problema.

Diante do exposto, o processo de construção de uma situação-problema não parece simples. Por isso, o próprio Meirieu (1998) propõe um caminho para construção, baseado em perguntas que devem ser respondidas previamente ao uso do dispositivo, com a finalidade de garantir características que a validem dentro de uma estratégia didática:

"1. Qual o meu objetivo? o que quero fazer com que o aluno adquira e que para ele representa um patamar de progresso importante?; 2. Que tarefa posso propor que requeira, para ser realizada o acesso a este objetivo (comunicação, reconstituição, enigma, ajuste, resolução, etc.)?; 3. Que dispositivo devo instalar para que a atividade mental permita, na realização de tarefa, o acesso ao objetivo? Que materiais, documentos, instrumentos devo reunir? Que instruções-alvo devo dar para que os alunos tratem os materiais para cumprir a tarefa? Que exigências devem ser introduzidas para impedir que os sujeitos evitem a aprendizagem?; 4. Que atividade posso propor que

DOI: Em andamento. 
permitam negociar o dispositivo segundo diversas estratégias? Como variar os instrumentos, procedimentos, níveis de orientação, modalidades de reagrupamento?" (p. 181)

Espera-se que na maioria das intervenções baseadas na estratégia de resolução de situações-problema, seja possível ao sujeito vencer os obstáculos que estão presentes nela, ou seja, que a solução esteja ao alcance deste sujeito e que ao mesmo tempo ele venha a obter tal solução sempre acompanhada da aprendizagem de novos conceitos, procedimentos e/ou atitudes.

Cabe destacar a questão da avaliação em atividades envolvendo situações-problema, que deve ser feita de três formas: diagnóstica, formativa e somativa (SIMÕES NETO, 2009). A primeira tem a função de conhecer o grupo de estudantes, para saber quais são os caminhos tomados para elaboração das situações-problema. A segunda tem por objetivo avaliar o momento de resolução das situações-problema, incluindo o uso do sistema de recursos. Por último, a avaliação somativa que avalia o final de todo o processo.

Diante do exposto, optamos por abordar o uso de situações-problema como estratégia didática no trabalho envolvendo as discussões acerca dos modelos atômicos, por tratar-se um conteúdo-chave para o ensino de química nas escolas, que tem se mostrado, principalmente no ensino público, inadequado pelas estratégias propostas para sua aprendizagem (SALGADO et al, 2009).

Em estudo realizado com alunos do Ensino Médio por Souza, Justi e Ferreira (2006), aprender modelos atômicos é considerado algo difícil de realizar. A maioria dos alunos não associa bem as analogias, tal como "modelo do pudim de passas" em relação ao átomo de Thomson ou o "sistema solar" do modelo de Rutherford. Cabe ao professor então, tomar conhecimento disto e refletir sobre como discutir o tema de forma a favorecer uma compreensão mais ampla do conteúdo científico e como utilizar as analogias. França, Marcondes e Carmo (2009) perceberam que a maior parte dos sujeitos de sua pesquisa não identificava em seus modelos representativos o núcleo e a eletrosfera, mesmo se tratando de palavras que estão presentes frequentemente na representação dos modelos atômicos escolares.

O uso de situações-problema como estratégia didática para o ensino do conteúdo de modelos atômicos se apresenta como uma interessante e válida proposta para tentar auxiliar o professor nos processos de ensino e aprendizagem. Podemos apresentar os objetivos deste trabalho: 1. Identificar as concepções dos estudantes de duas turmas do Primeiro Ano do Ensino Médio acerca do conteúdo de modelos atômicos;2. Analisar como a estratégia didática do uso das situações-problema pode auxiliar no processo de ensino e aprendizagem do conteúdo de Modelos Atômicos no Ensino Médio.

186 DOI: Em andamento. 


\section{Metodologia}

A pesquisa foi realizada com duas turmas noturnas do Primeiro Ano do Ensino Médio, de uma escola da rede estadual de educação de Minas Gerais, em Betim, região metropolitana de Belo Horizonte. Na turma I participaram das atividades 31 alunos e na turma II um conjunto de 33 alunos. Na escola as aulas têm duração média de quarenta minutos e não existem laboratórios para práticas experimentais.

A intervenção foi montada para um total de quatro encontros com cada turma, com duração de uma aula, e mais um momento de retorno. O percurso metodológico está descrito a seguir:

\section{Primeiro Momento da Intervenção: Avaliação Diagnóstica}

Elaboramos um questionário com quatro questões, com objetivo de auxiliar na construção das situações-problema. Para análise dos dados, classificamos as respostas em quatro categorias, de acordo com Simões Neto, Campos e Marcelino-Jr. (2013) e Silva (2013): Resposta Satisfatória (RS); Resposta Pouco Satisfatória (RPS); Resposta Insatisfatória (RI) e Sem Resposta (SR). As questões e os critérios utilizados estão no quadro 1 :

DOI: Em andamento. 
Quadro 1-Questionário e Critérios para as Respostas

\begin{tabular}{|c|c|}
\hline $\begin{array}{l}\text { 1. O que você entende por modelo atômico? } \\
\text { Comente. }\end{array}$ & $\begin{array}{l}\text { RS: se abordasse como forma em que filósofos e } \\
\text { cientistas tentavam descrever o átomo ou a } \\
\text { matéria; RPS: se abordasse apenas como uma } \\
\text { tentativa de descrever o átomo; RI: não } \\
\text { abordasse a questão da descrição do átomo ou } \\
\text { matéria. }\end{array}$ \\
\hline $\begin{array}{l}\text { 2. Cite para cada um dos modelos atômicos } \\
\text { quais são as principais falhas e acertos nos } \\
\text { modelos de Dalton, Thomson, Rutherford e } \\
\text { Bohr? Justifique. }\end{array}$ & $\begin{array}{l}\text { RS: se citasse pelo menos um erro e um acerto } \\
\text { de cada em relação ao modelo atual; RPS: se } \\
\text { abordasse apenas um erro ou acerto de cada } \\
\text { em relação ao modelo atual; RI: fora das duas } \\
\text { classificações anteriores. }\end{array}$ \\
\hline $\begin{array}{l}\text { 3. Considerando os modelos até aqui } \\
\text { discutidos, como você desenharia o átomo de } \\
\text { hidrogênio, sabendo que ele tem um próton, } \\
\text { um elétron e nenhum nêutron. Descreva a } \\
\text { figura. }\end{array}$ & $\begin{array}{l}\text { RS: se desenhasse o átomo semelhante ao } \\
\text { apresentado pelo modelo de Rutherford-Bohr; } \\
\text { RPS: se fosse capaz de separar o átomo como } \\
\text { núcleo e eletrosfera; RI: fora das duas } \\
\text { classificações anteriores. }\end{array}$ \\
\hline $\begin{array}{l}\text { 4. De acordo com a teoria de Bohr, o átomo é } \\
\text { formado por uma massa centrada no núcleo e } \\
\text { uma eletrosfera, onde estão os elétrons. } \\
\text { Baseado nesta teoria, você acredita que em } \\
\text { uma mesa de madeira, que é formada por } \\
\text { átomos, existam partes vazias? Por quê? }\end{array}$ & $\begin{array}{l}\text { RS: se a resposta fosse "sim" e explicasse os } \\
\text { espaços vazios pela eletrosfera; RPS: se "sim", } \\
\text { mas com outra explicação; RI: se respondesse } \\
\text { "não". }\end{array}$ \\
\hline
\end{tabular}

\section{Elaboração das Situações-Problema e do Sistema de Recursos}

Para elaborar as situações-problema, recorremos as ideias de Meirieu (1998), que sugere que os conhecimentos prévios dos alunos sejam levados em conta como uma forma de promover a interação problema/resposta. Para isso, levamos em consideração os resultados obtidos na análise do questionário aplicado na primeira etapa da intervenção.

Elaboramos duas situações-problema que fornecessem condições para provocar nos alunos uma ou mais operações mentais, tais como: a dedução, a indução, a dialética ou mesmo divergências requeridas para que eles conseguissem vencer o obstáculo proposto (MEIRIEU, 1998; BATINGA; ALMEIDA; CAMPOS, 2005).

A primeira visava suscitar no aluno os motivos que levaram Rutherford a elaborar a teoria atômica, com base nos resultados experimentais, e a segunda de usar um contexto bem comum

188 DOI: Em andamento.

R. Bras. de Ensino de C\&T 
ao cotidiano dos alunos- a explosão de fogos de artifício, aqui relacionada com a teoria atômica de Bohr:

SP1: $O$ experimento de Rutherford, feito através da orientação do mesmo ao aluno de doutorado em Física, Hans Geiger e ao professor Ernest Marsden. O experimento consistiu na emissão de partículas $\alpha\left(\mathrm{He}^{2+}\right)$ sobre uma placa muito fina de ouro ( $\mathrm{Au}$ ), com um anteparo fosforescente, que sob radiações alfa, emite luz, possibilitando observar onde ocorreriam as colisões, como na figura 1.

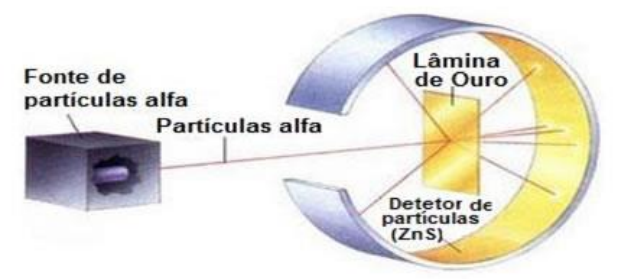

Figura 1 - O Experimento de Rutherford.

(Fonte: www.alunosonline.com.br)

A partir das conclusões deste experimento, Rutherford pode então elaborar uma teoria que melhorava as ideias de Thomson para o átomo. Baseado na figura e em seus conhecimentos, quais as conclusões de Rutherford ao observar os resultados do experimento de Geiger-Marsden?

SP2: O conhecimento atual sobre a estrutura dos átomos nos indica que seus elétrons têm diferentes quantidades de energia: uns são mais energéticos, outros menos. Sabe-se ainda que esta quantidade de energia é fixa e denominada nível de energia. Segundo estudos de Bohr, os elétrons que estão nos níveis de menor energia ocupam uma região mais próxima do núcleo; os que estão em niveis de maior energia ocupam regiões mais afastadas. Sabe-se ainda que existem transições eletrônicas entre níveis distintos. Baseado no texto anterior e nos conhecimentos adquiridos nas aulas de química, explique o fenômeno da liberação de luzes com cores diferentes, ocorrido nos fogos de artifícios.

Como sistema de recursos para resolução das situações problemas, elaboramos um material didático textual de nove páginas, usado como instrumento de consulta pelos estudantes durante a intervenção.

Tanto o material textual quanto as aulas preparadas não levaram em consideração o modelo do átomo quântico, pois exige um alto grau de abstração e não se apresenta como inerentemente melhor que a visão clássica, quando pensamos na aplicação em contextos socioculturais dos estudantes do Ensino Médio (EICHLER; DEL PINO, 2000). 


\section{Segundo, Terceiro e Quarto Momentos da Intervenção}

Para as aulas (segundo e terceiro momentos da intervenção), usamos uma abordagem comunicativa, na dimensão de um discurso dialógico e interativo, onde professor-pesquisador buscou a voz dos estudantes, incentivando a participação e levando em consideração tudo que falaram (MORTIMER; SCOTT, 2002). O professor-pesquisador fez o uso do diálogo e do quadro branco para anotar aquilo que os alunos poderiam necessitar de pesquisar para auxiliar na elaboração das respostas das situações-problema posteriormente.

No quarto momento da intervenção, dividimos os estudantes em grupos de aproximadamente quatro componentes e entregamos as duas situações-problema. Era permitido e incentivado o debate interno entre os grupos, mas não poderiam consultar materiais adicionais, nem os grupos vizinhos. Analisamos as respostas como satisfatórias ou não-satisfatórias mediante a transposição do obstáculo instalado em cada situação-problema.

\section{Momento de Retorno}

Escolhemos para participar do momento de retorno três alunos de cada turma, usando como critério de seleção, na ordem: disponibilidade de tempo, interesse e participação durante a intervenção didática.

Elaboramos um questionário para avaliar as potencialidades da estratégia didática baseada nas situações-problema. Seis perguntas foram pensadas e estão descritas a seguir:

1. O que você achou do trabalho envolvendo situações-problema?

2. Você achou as situações-problema fáceis ou difíceis? Por quê?

3. Após a resolução das situações-problema, você acredita que aprendeu algo novo sobre modelos atômicos?

4. As situações-problema foram resolvidas em Grupo. Você responderia diferente do seu grupo caso a atividade fosse individual?

5. O Modelo Atômico de Rutherford foi tema da primeira situação-problema. Você seria capaz de explicar tal modelo com poucas palavras?

6. Você gostaria de trabalhar com situações-problema também em outros conteúdos da química? Por quê?

Antes de responder o questionário, os estudantes puderam ter contato com as respostas do seu grupo para que pudessem refletir sobre o que responderam.

Analisamos as respostas individualmente, buscando identificar quais foram os pontos positivos e negativos apontados pelos estudantes.

190 DOI: Em andamento.

R. Bras. de Ensino de C\&T 


\section{Resultados e Discussão}

Apresentamos os resultados em três partes: análise da avaliação diagnóstica, análise da resolução das situações-problema e análise do questionário aplicado no momento de retorno.

\section{Análise da Avaliação Diagnóstica}

Na primeira questão, nas duas turmas trabalhadas, não emergiram respostas satisfatórias. Devido ao caráter autoexplicativo do tema trabalhado, tivemos algumas respostas pouco satisfatórias, conforme tabela 1:

Tabela 1 - Respostas à primeira questão do Quadro 1.

\begin{tabular}{ccc}
\hline Classificação da Resposta & Turma I & Turma II \\
\hline RS & 0 & 0 \\
\hline RPS & $46 \%$ & $44 \%$ \\
\hline RI & $43 \%$ & $45 \%$ \\
\hline NR & $11 \%$ & $11 \%$ \\
\hline
\end{tabular}

Mesmo sem ocorrência de respostas satisfatórias, os resultados demonstram um conhecimento, mesmo que mínimo, sobre modelos atômicos, talvez pela evidência que os átomos possuem fora do meio científico-escolar. Alguns exemplos de respostas pouco satisfatórias e insatisfatórias:

RPS: "Modo como os átomos (menor partícula em que se divide uma matéria) são classificados".

RI: "São moléculas".

A segunda questão apresentou o maior nível de dificuldade nas respostas, alto índice de respostas em branco e respostas insatisfatórias, além de não emergir nenhuma resposta satisfatória. A tabela 2 apresenta a distribuição dos resultados:

Tabela 2 - Respostas à segunda questão do Quadro 1.

\begin{tabular}{ccc}
\hline Classificação da Resposta & Turma I & Turma II \\
\hline RS & 0 & 0 \\
\hline RPS & $25 \%$ & $11 \%$ \\
\hline RI & $32 \%$ & $44,5 \%$ \\
\hline NR & $43 \%$ & $44,5 \%$ \\
\hline
\end{tabular}


Tal questão exigia conhecer bem os modelos atômicos. Talvez por isso o índice de respostas satisfatórias e pouco satisfatórias tenha sido tão pequeno. Para apontar falhas e acertos é necessário entender o que cada modelo apresenta, e conseguir compará-lo com os demais. Seguem exemplos de respostas em cada categoria onde houve ocorrência:

RPS: "Falhas: O fato de não possuir núcleo (no começo). Acertos: Possuir cargas positivas, cargas negativas, e neutras. Possuir um núcleo e ao redor do núcleo uma eletrosfera".

RI: "As falhas são as radiações".

Na terceira questão, surgem algumas respostas consideradas satisfatórias nas duas turmas. A tabela 3 apresenta a distribuição das respostas:

Tabela 3 - Respostas à terceira questão do Quadro 1.

\begin{tabular}{ccc}
\hline Classificação da Resposta & Turma I & Turma II \\
\hline RS & $11 \%$ & $18,5 \%$ \\
\hline RPS & $14 \%$ & $15 \%$ \\
\hline RI & $61 \%$ & $55,5 \%$ \\
\hline NR & $14 \%$ & $11 \%$ \\
\hline
\end{tabular}

Alguns fatores extraescolares podem ter ajudado para que os alunos desenhassem o átomo de hidrogênio como esperado, como por exemplo, a animação "Jimmy Neutron", onde o personagem principal usa uma camisa com o desenho de um átomo semelhante ao modelo de Rutherford. Ainda assim, a ocorrência de respostas pouco satisfatórias foi alta. Na figura 2, um exemplo de resposta satisfatória, pouco satisfatória e insatisfatória:

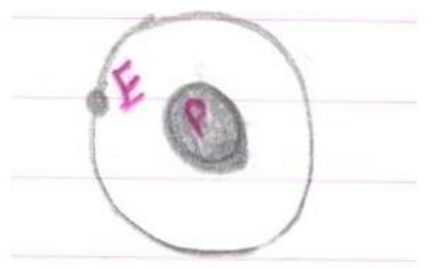

(A)

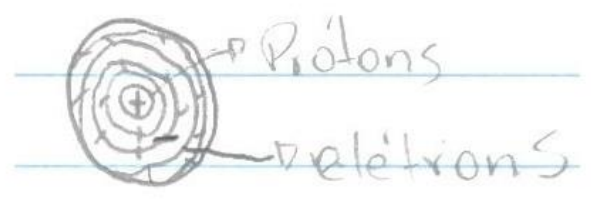

(B)

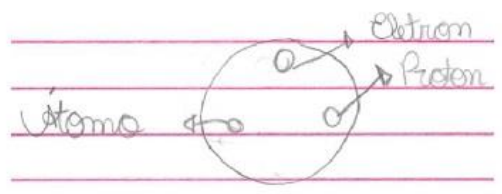

(C)

Figura 2 - Resposta Satisfatória (A), Resposta Pouco Satisfatória (B) e Resposta Insatisfatória (C) para a terceira questão

$\mathrm{Na}$ quarta questão, tivemos uma diferença significativa entre as turmas na ocorrência das respostas, como é mostrado na tabela 4: 
Tabela 4-Respostas à quarta questão do Quadro 1.

\begin{tabular}{ccc}
\hline Classificação da Resposta & Turma I & Turma II \\
\hline RS & $18 \%$ & $44 \%$ \\
\hline RPS & $39 \%$ & $30 \%$ \\
\hline RI & $25 \%$ & $22 \%$ \\
\hline NR & $18 \%$ & $4 \%$ \\
\hline
\end{tabular}

A diferença nas respostas se concentra no entendimento maior dos estudantes da turma II sobre a eletrosfera, como um espaço quase vazio, em contrapartida ao denso núcleo central. Seguem exemplos de respostas satisfatória, pouco satisfatória e insatisfatória

RS: "Sim. Já que a mesa é formada de átomos, e cada átomo tem seu espaço vazio, na eletrosfera, a mesa terá partes vazias, mas muito pequenas e não podem ser vistas a olho nu".

RPS: "Acredito que sim, se a mesa for feita de madeira, pode ter sim partes ocas, espaços vazios". RI: "Não, porque tem os furos na mesa".

\section{Análise das Respostas às Situações-problema}

As respostas, quando apresentadas, foram transcritas originalmente como feitas pelos alunos. A turma I foi dividida em seis grupos identificados como grupos $A$ até $F$, enquanto a turma Il foi dividida em sete grupos identificados como grupos de G a M. As situações-problema foram analisadas independentes entre si, para cada grupo.

\section{$\underline{\text { TURMA I }}$}

A turma I apresentou pouco interesse -pouca discussão entre os alunos - e isto ficou evidente nas respostas dos grupos, com destaque para o grupo $A$, que sequer apresentou resposta às situações-problema. O grupo B também apresentou dificuldades, pois copiaram trechos do enunciado do problema como prováveis respostas. Não houve discussão ou questionamento com o professor-pesquisador em nenhum momento.

O grupo C, para solucionar a primeira situação-problema, tentou explicar os desvios das partículas alfa no experimento pela natureza elétrica positiva, mas não explicaram o comportamento das partículas que não sofriam desvio. A segunda situação-problema também foi respondida de forma não satisfatória por este grupo - embora tenham comentado que átomos diferentes causam explosões de cores diferentes, a causa não foi explicada. 
SP1: "Se as cargas elétricas dos átomos das duas substâncias forem iguais ocorre um desvio do percurso dos átomos dessas substâncias" (grupo C)

SP2: "Dependendo dos átomos presentes, as explosões (sic) adquirem cores diferentes." (grupo C)

O grupo D apresentou uma solução satisfatória para a primeira situação-problema, uma demonstração de entendimento parcial do assunto, apesar de não abordarem questões relativas ao núcleo, no modelo atômico de Rutherford. Na segunda SP, observamos também um certo conhecimento, embora com uma argumentação um tanto superficial. Ainda assim, conseguiram propor as melhores soluções entre os grupos da turma I.

SP1: "No experimento de Rutherford os raios de radiação alfa, a maioria, passavam direto na placa de ouro, isso porque os átomos possuem espaços vazios." (grupo D)

SP2: "Quando o elétron se solta ele pula o nível de energia liberando uma luz." (grupo D)

Os grupos $\mathrm{E}$ e $\mathrm{F}$ apresentaram respostas insatisfatórias para as duas situações-problema. No caso do grupo $\mathrm{E}$, apenas trechos dos enunciados foram copiados, enquanto que no outro grupo, as respostas foram pensadas, no entanto, o obstáculo não foi transposto e a situação-problema não foi respondida de maneira satisfatória.

\section{TURMA II}

A turma II apresentou um comportamento melhor durante a discussão, mostrando mais interesse, compromisso e sempre levantando questões e dúvidas. O debate entre os grupos foi mais evidente. No entanto, alguns grupos não conseguiram transpor o obstáculo instalado nas situações-problema, dando respostas não-satisfatórias para ambas: caso dos grupos G, J e I. O grupo $\mathrm{K}$, embora não tenha dado resposta alguma para a primeira situação-problema, mostrou uma resposta no caminho correto para a segunda, embora não associem esse movimento às mudanças de órbitas:

SP2: "Quando no átomo o elétron se move, libera energia em forma de luz ". (grupo K)

Os grupos $\mathrm{H}, \mathrm{L}$ e $\mathrm{M}$ conseguiram responder de maneira satisfatória as duas situaçõesproblema. Destacamos o grupo $\mathrm{H}$, que apresentou a visão de átomo de Rutherford para explicar o experimento, além de fornecer uma boa visão das transições eletrônicas na segunda situaçãoproblema, como podemos ver na figura 3 :

SP1: "Átomo possui um núcleo muito pequeno, e positivamente carregado e rodeado por uma nuvem de elétrons quase vazia." (grupo $\mathrm{H}$ ) 
SP2: "Um elétron se move em uma órbita circular, estável, sobre uma atração coulombiana. Quando esse átomo é aquecido os elétrons se movem (exemplo na figura) e no percurso de volta sua energia é liberada em forma de luz." (grupo H)

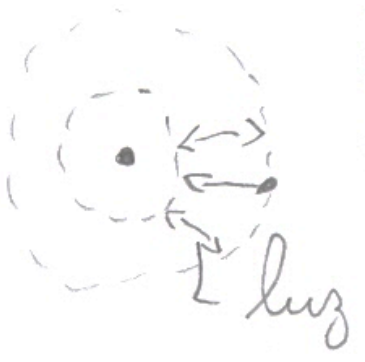

Figura 3 - Representação da transição eletrônica na resposta do grupo $\mathrm{H}$

O grupo L apresentou, na primeira questão algumas das conclusões de Rutherford sobre a estrutura do átomo, de maneira satisfatória. Na segunda situação-problema, os alunos do grupo L explicaram por movimentação que os elétrons liberam energia na forma de luz e ainda que a cor da luz pode variar conforme a energia também varia, mas foram imprecisos ao deixarem de mencionar os níveis de energia, sendo classificada como uma resposta parcialmente satisfatória.

SP1: "Rutherford conclui que o átomo tem a maior parte dele como um espaço vazio e que maioria de sua massa se concentra no núcleo." (grupo L)

SP2: "Quando no átomo, os elétrons se movem e liberam energia em forma de luz. A cor da luz varia de acordo com a diferença de energia na movimentação." (grupo L)

Por fim, o grupo $\mathrm{M}$ apresentou texto confuso na resposta à segunda situação-problema, por não tratar a transição do elétron para um nível interno como o momento em que há liberação de energia. No entanto, apresentou o motivo das cores diferentes para os fogos de artifício.

SP1: "Átomo: núcleo muito pequeno, positivamente carregado e rodeado por uma nuvem de elétrons. A massa desse átomo estaria quase totalmente concentrada no núcleo (modelo planetário)." (grupo M)

SP2: "As luzes refletem cores diferentes porque os elétrons possuem energias diferentes. Na transição de energia o elétron começa em uma energia menor a cada nível que avança aumenta sua energia." (grupo M)

\section{Análise do questionário Aplicado no Momento de Retorno}

O questionário final foi aplicado a seis alunos, sendo três da turma I os outros três da turma II. Eles foram selecionados pelo interesse em participar da intervenção e foram nomeados como cores: Marrom, Bege e Cinza, para a turma I; Branco, Preto e Vermelho, para a turma II. A partir 
das respostas dadas ao questionário, procuramos analisar os pontos positivos e a dificuldade da metodologia, e ainda se eles reconhecem a ajuda das situações-problema no entendimento de modelos atômicos.

\section{O que você achou do trabalho envolvendo situações-problema?}

As respostas mostram opiniões semelhantes, todos afirmaram que foi bom trabalhar com situações-problema, dentro da proposta de intervenção apresentada, pois é método de ensino e aprendizagem que exige do aluno o raciocínio, pois cabe a cada um, com ajuda do sistema de recursos e dos colegas, construir o conhecimento necessário para que possa transpor o obstáculo. Destacamos duas respostas, uma de cada turma:

“Eu gostei do trabalho, porque ele ajuda a desenvolver a sua mente. Com respostas que você dá sem ter nenhum texto como base". (Marrom)

"Achei esse trabalho muito interessante, porque, força um pouco mais nosso pensamento, nossas ideias, fazendo com que pudéssemos aprender mais". (Preto)

\section{Você achou as situações-problema fáceis ou difíceis? Por quê?}

Com exceção do aluno Marrom, os estudantes da turma I acharam difícil trabalhar com as situações-problemas, porém, atribuíram a dificuldade ao conteúdo de modelos atômicos. Já a turma II aponta dificuldade moderada, mas destacam que quando o conteúdo é aprendido, o obstáculo é facilmente transposto e a dificuldade só aparece quando a construção do conhecimento não ocorre.

"Fica no meio termo, pois como eu havia dito na questão anterior envolvia conteúdos conhecidos (mas que partes já tinha esquecido, mas foi bom relembrar) e conteúdos desconhecidos (foi bom pegar um pouco do que vem pela frente)". (Branco)

"Eu achei fáceis, pois gosto de ler revistas, jornais, assistir televisão, tenho conhecimento, por isso foi fácil" (Marrom)

"Difícil. Pois eu não sei muito de química, e na verdade não entendo nada. " (Bege)

\section{Após a resolução das situações-problema, você acredita que aprendeu algo novo sobre modelos atômicos?}

As respostas convergiram no sentido de que situações-problema acrescentaram algo novo, o que valida a estratégia de ensino. Pelas respostas, percebemos também a importância do material textual e das aulas como sistema de recursos.

196 DOI: Em andamento.

R. Bras. de Ensino de C\&T 
"Sim, porque do meu ponto de vista eu via os modelos atômicos de um jeito, e depois da SP eu passei a ter outro ponto de vista". (Marrom)

"Sim, porque eu entendi melhor algumas coisas". (Bege)

"Sim, pois a aula e a tarefa me apresentaram vários fatores que eu desconhecia". (Branco)

"Sim. Aprendemos mais sobre modelos atômicos e descobrimos coisas que nunca ouvimos falar antes". (Preto)

4. As situações-problema foram resolvidas em Grupo. Você responderia diferente do seu grupo se fosse individual?

Os alunos Marrom e Cinza mostram nas respostas a dificuldade de trabalho observada na turma I, com grupos pouco participativos e desinteressados.

"Eu respondi sozinho, meu grupo só tinha 'gênios'”.(Marrom)

"Não. Pois eu respondi quase sozinho". (Cinza)

Ao contrário da turma I, todos os alunos da turma II mostram que trabalhar em grupo ajuda a vencer o obstáculo proposto ao poder juntar os conhecimentos para propor a solução e ainda destacando a importância individual da participação na elaboração desta solução.

"Não, pois foi resolvido com alguns palpites meus que combinaram com os palpites dos outros componentes do grupo". (Branco)

"Não. Porque todos aprendemos juntos, então nossas ideias eram parecidas, então não mudaria a resposta". (Preto)

"Não, porque as respostas em grupo foram formadas com a ajuda de todos inclusive eu". (Vermelho)

5. O Modelo Atômico de Rutherford foi tema da primeira SP. Você seria capaz de explicar tal modelo com poucas palavras?

Bege, cinza, marrom e branco explicaram não o modelo atômico de Rutherford, mas o experimento descrito na situação-problema. Talvez o apelo visual dado pela figura possa ter dirigido a esse tipo de resposta. Apresentamos a resposta de Cinza:

"Era uma caixa de chumbo com um tubo com radiação a radiação ia de encontro a uma folha de ouro alguns raios passavam direto e outros desviavam". (Cinza)

Preto e vermelho, sem consulta a nenhum material, conseguiram explicar o modelo atômico de Rutherford:

DOI: Em andamento. 
"No modelo de Rutherford um átomo tem um núcleo pequeno no centro que é envolvido pela eletrosfera." (Preto)

"Possui um núcleo pequeno que está rodeado de elétrons carregados".

\section{Você gostaria de trabalhar com SP em outros conteúdos? Por quê?}

Apenas um aluno dentre os seis indica que não gostaria de trabalhar novamente com esta estratégia, mas ainda assim apresenta um argumento inconsistente, uma vez que o trabalho com situações-problema é encontrado na literatura também para outros conteúdos e disciplinas escolares.

"Não. Porque nas outras matérias não se encaixaria". (Bege)

Pelo exposto por Branco, Preto e Marrom, a estratégia mostra validade e, mesmo colocando o aluno numa posição diferente do ensino tradicional, exigindo mais trabalho, agradou aos participantes:

"Sim, pois é muito interessante e gostei muito de aprender e gostaria muito de saber mais." (Branco)

"Sim. Porque nosso aprendizado com certeza seria maior e melhor". (Preto)

\section{Algumas Considerações}

O uso das situações-problema estimula o raciocínio dos estudantes, pois quando eles se deparam com o obstáculo e constroem uma solução para o problema, ocorre situação de aprendizagem. Percebemos a partir das respostas ao questionário final que a estratégia foi bem aceita pelos estudantes e que as situações-problemas criadas atingiram o objetivo proposto, fazendo com que os alunos buscassem vencer este obstáculo, construindo o conhecimento quando possível.

Destacamos a realidade do trabalho com turmas noturnas, que são diferentes das turmas diurnas no perfil dos alunos. Geralmente, os estudantes deste turno são mais velhos, já estão inseridos no mercado de trabalho e buscam a complementação da educação básica para melhoria de vida, em busca de uma promoção ou novo emprego, para aumentar a renda e sua qualidade de vida. Assim, chegam à sala de aula já cansados da jornada diurna e pouco produzem, sendo evasão e desistência situações bastante comuns, pois o que aprendem nas escolas não se relaciona efetivamente com seu cotidiano, em casa ou no trabalho (GONÇALVES; PASSOS; PASSOS, 2005). Porém, é importante evidenciar a importância no entendimento dos modelos atômicos para a compreensão dos conteúdos subsequentes da química, o que justifica a relevância em trabalhar com essa temática nesta pesquisa.

198 DOI: Em andamento.

R. Bras. de Ensino de C\&T 
As respostas à avaliação diagnóstica mostraram que a maioria dos alunos não possuía concepções científicas definidas para modelos atômicos. Acreditamos que eles ainda não tinham assistido as aulas de modelos atômicos até o momento da intervenção, sendo a primeira experiência deles com o conteúdo abordado. A ideia de átomo como uma pequena entidade que forma a matéria parece ser aceita pelos estudantes, porém, entender a natureza dessas partículas, partes que as compõem, quais as principais características de cada modelo formulado e porque eles são confrontados por outras propostas não fazem parte dos conhecimentos prévios apresentados pelos estudantes. O grande número de respostas pouco satisfatórias e insatisfatórias nos levam a esta conclusão.

A maioria dos alunos da turma I se comportou de forma desatenta, com pouco ou nenhum interesse em aprender durante a intervenção, enquanto que uma parcela significativa dos alunos da turma II demonstrou interesse, fato que fica evidenciado ao analisarmos as soluções propostas para as situações-problema - as respostas para a segunda turma se mostraram mais efetivas, o que evidencia o valor da motivação inicial em participar de qualquer tipo de atividade dentro de uma estratégia didática.

De forma geral, foram consideradas como satisfatórias 35\% das respostas apresentadas. Vários são os fatores que podem justificar este resultado, alguns intrínsecos ao próprio conteúdo escolhido, a saber: nível de abstração exigido para uma visão microscópica da matéria, abordagem classicamente histórica e pequena relação direta com atividades do cotidiano dos estudantes. Ainda, possivelmente existem outros fatores relacionados a gestão escolar e planejamento do ensino e a aparente falta de interesse dos alunos (principalmente na turma I). No entanto, consideramos os resultados satisfatórios, pois o trabalho com situações-problema demanda um esforço do estudante, o que é pouco comum nas escolas atualmente, principalmente no turno escolhido para a pesquisa.

É considerável a diferença no resultado entre as duas turmas participantes da pesquisa: enquanto a turma I apresentou apenas $17 \%$ de respostas classificadas como satisfatórias para as situações-problema, a turma II teve $50 \%$, das respostas nesta classificação. Já comentamos o comportamento diferente das turmas em relação à estratégia. Essa diferença pode ser explicada pelo engajamento dos estudantes na participação durante a intervenção. Embora $17 \%$ de respostas satisfatórias pareça um resultado ruim, é evidente o avanço na compreensão dos conceitos pelos estudantes das duas turmas. Acreditamos que a estratégia didática se mostrou eficiente.

Por fim, analisando cada situação-problema de forma independente, podemos verificar dificuldades relativas para cada uma: a primeira situação-problema teve $34 \%$ de respostas consideradas como satisfatórias, enquanto a segunda 39\%, indicando nível de dificuldade equivalente. 


\section{Referências}

AZEVEDO, M. C. P. Ensino por Investigação: Problematizando as atividades em sala de aula. In: CARVALHO, A. M. P. Ensino de Ciências: Unindo a pesquisa e a prática. São Paulo:Thomson, 2004.

BATINGA, V. T. S.; ALMEIDA, M. A. V.; CAMPOS, A. F. Concepções de professores de química do Ensino Médio sobre a resolução de situações-problema. Revista Brasileira de Pesquisa em Educação em Ciências. São Paulo, v. 5, n. 3, p. 25-37, 2005.

BATINGA, V. T. S.; TEIXEIRA, F. M.O que pensam os professores de química do Ensino Médio sobre o conceito de problema e exercício. In: VII Encontro Nacional de Pesquisa em Educação em Ciências, 2009, Florianópolis, Anais... Belo Horizonte: ABRAPEC, 2009.

BATINGA, V. T. S.; TEIXEIRA, F. M. A Abordagem de Resolução de Problemas por uma professora de Química: Análise de um problema sobre a Combustão do Álcool envolvendo o conteúdo de Estequiometria. Revista Brasileira de Ensino de Ciência e Tecnologia. Ponta Grossa, v. 7, n. 1, p. 24-52, 2014.

BRASIL. Orientações curriculares para o ensino médio: ciências da natureza, matemática e suas tecnologias. Brasília (DF), Secretaria de Educação Básica: MEC, 2006.

CÂMARA DOS SANTOS, M. Algumas Concepções sobre o ensino-aprendizagem em matemática. Educação Matemática em Revista. São Paulo, n. 12, p. 11-15, 2002.

EICHLER, M.; DEL PINO, J. C. Computadores em Educação Química: Estrutura Atômica e Tabela Periódica. Química Nova. São Paulo, v. 23, n. 6, p. 835-840,2000.

FRANÇA, A. C. G.; MARCONDES, M. E. R; CARMO, M. P. Estrutura Atômica e Formação dos íons: Uma análise das ideias dos alunos do 3ํ ano do Ensino Médio. Química Nova na Escola. São Paulo, v. 31, n. 4, p. 275-282, 2009.

FREIRE, P. Pedagogia do Oprimido.44. ed. Rio de Janeiro:Paz e Terra, 2005.

GONÇALVES, L. R.; PASSOS, S. R. M. M. S.; PASSOS, A. M. Novos rumos para o Ensino Médio Noturno - como e por que fazer? Ensaio: Avaliação de Políticas Públicas Educacionais. Rio de Janeiro, v. 13, n. 48, p. 345-360, 2005.

MEIRIEU, P. Aprender... sim, mas como? 7. ed. Porto Alegre: Artmed, 1998.

MORTIMER, E. F.; SCOTT, P.; Atividade Discursiva nas salas de aula de ciências: Uma ferramenta Sociocultural para analisar e planejar o ensino. Investigações em Ensino de Ciências. Porto Alegre, v.7, n.2, p. 286-306, 2002.

MORTIMER, E. F.; MACHADO, A. H.; ROMANELLI, L. I. A proposta curricular de química do estado de Minas Gerais: fundamentos e pressupostos. Química Nova. São Paulo, v. 23, n. 2, p. 273-283, 2000. 
POZO, J. I.; GÓMEZ CRESPO, M. A. A Aprendizagem e o Ensino de Ciências: Do conhecimento cotidiano ao conhecimento científico. 5 ed. Porto Alegre: Artmed, 2009.

SALGADO, T. D.; HAINZENREDER, G. O.; SILVA, S. M.; DEL PINO, J. C. Um objeto de aprendizagem para trabalhar conceitos de radioatividade e modelos atômicos na formação de professores de química. In: VII Encontro Nacional de Pesquisa em Educação em Ciências, 2009, Florianópolis, Anais... Belo Horizonte: ABRAPEC, 2009.

SILVA, F. C. V. Resolução de uma Situação-Problema Sobre Radioatividade para Construção de Conceitos de Radioatividade no Ensino Superior de Química. 2013. 115 f. Dissertação (Mestrado em Ensino das Ciências) - Programa de Pós-Graduação em Ensino das Ciências, Universidade Federal Rural de Pernambuco, Recife.

SIMÕES NETO, J. E. Abordando o conceito de isomeria por meio de situações-problema no Ensino Superior de química. 2009. 120 f. Dissertação (Mestrado em Ensino das Ciências) - Programa de Pós-Graduação em Ensino das Ciências, Universidade Federal Rural de Pernambuco, Recife.

SIMÕES NETO, J. E.; CAMPOS, A. F.; MARCELINO-JR., C. A. C. Abordando a isomeria em compostos orgânicos e inorgânicos: uma atividade fundamentada no uso de situações-problema na formação inicial de professores de Química. Investigações em Ensino de Ciências. Porto Alegre, v. 18, n. 2, p. 327-346, 2013.

SOUZA, V. C. A.; JUSTI, R. S. J.; FERREIRA, P. F. M. Analogias utilizadas no ensino dos Modelos Atômicos de Thomson e Bohr: Uma análise crítica sobre o que os alunos pensam a partir delas. Investigações em Ensino de Ciências. Porto Alegre, v. 11, n. 1, p. 7-28, 2006.

Mauro de Souza Lima Prates Júnior é licenciado em Química pela Universidade Federal de Minas Gerais (2011), e graduando em Engenharia Química pelo Centro Universitário UMA-MG. E-mail: maurosgb@gmail.com

José Euzebio Simões Neto é licenciado em química pela Universidade Federal de Pernambuco (2005), mestre em ensino das ciências pelo Programa de Pós-graduação em Ensino das Ciências da Universidade Federal Rural de Pernambuco e professor do departamento de Química da Universidade Federal Rural de Pernambuco.E-mail: euzebiosimoes@gmail.com 